\title{
THE INFLUENCE OF PARITY AND MATERNAL PREIMMUNIZATION ON FETAL SURVIVAL IN MICE
}

\author{
D. P. HUMBER, G. MAHOUY, S. GHINN AND R. D. BARNES
}

Clinical Research Centre, Watford Road, Harrow, Middlesex HA1 $3 U \mathcal{J}$

(Received 3rd March 1974)

A common immunological consequence of pregnancy is that the mother may become sensitized to fetal or paternal antigens (Goodlin \& Herzenberg, 1964; Kaliss \& Dagg, 1964; Soren, 1967). Recently, Maroni \& Parrott (1973) have demonstrated that cell-mediated immunity against paternal antigens increases with parity. We have attempted to compare the results of normal parity with artificial immunization designed to simulate maternal sensitization to paternal antigens.

Outbred TO mice, of approximately the same age ( 6 to 7 weeks), conventionally housed at the M.R.G. Glinical Research Centre, were used in this study. Two groups of mice were investigated: (1) a group of parous mice which had been mated so that they reached their final parities at approximately the same age (29 to 34 weeks); (2) a group of virgin females which had been sensitized to paternal antigens. Females were immunized at weekly intervals with intraperitoneal injections of $50 \mu$ l heparinized whole blood from males destined to become their mates. A cycle of three injections was regarded as representing the immunization occurring (1) at implantation, (2) at midpregnancy, and (3) during late and ante-partum pregnancy. The cycle of three injections was then repeated 7 days after the last injection, each cycle representing one artificial parity. No attempt was made to equalize the number of injections given to the groups. Mice from both groups were subsequently mated 4 to 6 weeks after either their last litter or their last cycle of immunization. Females were examined daily and the detection of a vaginal plug was considered to represent Day 1 of pregnancy. All females were killed on the 18th day of pregnancy. The uterus was examined and the total numbers of live and dead fetuses were noted. Dead fetuses were classified according to the occurrence of death during early, middle or late pregnancy by the criteria of McLaren \& Michie (1959). Fetuses and placentae were dissected free of their membranes and fixed in $10 \%$ buffered formalin for at least 1 week. These were subsequently blotted and weighed separately to the nearest milligram. Fetuses were sexed by macroscopic appearance.

The effects of parity and immunization to paternal antigens on placental weight, fetal weight and litter size were studied by regression analyses. Litter sizes were corrected to the mean age of the mother using the within-parity pooled regression coefficient of number of fetuses on age. To test for a trend in fetal and placental weights, regression analysis was carried out on the $\log _{10}$ mean fetal and placental weights. The age of the mother was again included 
as an independent variable, and also the numbers of live fetuses and those dying in middle or late pregnancy to allow for the effect of litter size on fetal and placental weight (Healy, McLaren \& Michie, 1960).

The mean number of fetuses, both total and live, at each parity is shown in Text-fig. 1. The total and live litter size showed a significant increase with immunization (Table 1). With increasing natural parity, there was also a significant increase in total litter size, with a smaller and not quite significant increase in live litter size. The mean fetal death rate remained relatively constant in both the natural and artificial parities. Fetal weight increased significantly with parity (Table 2), but there was no change in placental weight with increasing parity. Fetal and placental weight did not alter with immunization.

The sex ratio in both groups remained relatively constant and did not change significantly with parity.

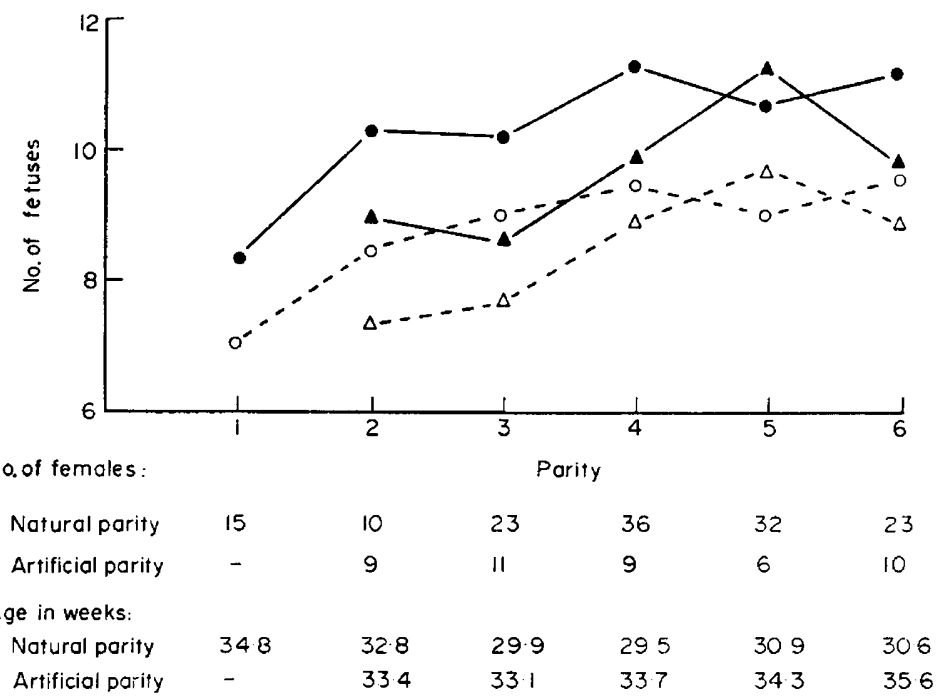

TEXT-FIG. 1. The number of mouse fetuses (total and live) corrected to the mean age of the mother at each parity. @, Total no. of fetuses after natural parity; $O$, no. of live fetuses after natural parity; $\Delta$, total no. of fetuses after artificial parity; $\Delta$, no. of live fetuses after artificial parity.

We were unable to confirm the increase in placental weight that has been associated with multiparity in the mouse (Sugiyama, 1961; McCarthy, 1965; Hetherington, 1972a). Moreover, in our study, fetal weight increased with parity, whereas Sugiyama (1961) found no change and Hetherington (1972a) described a decrease. No satisfactory explanation can be found to account for these differences. It should be noted, however, that in all three of the above investigations the effects of age and parity were confounded, whereas the experiment described here examined the effects of parity alone. An alternative or supplementary explanation is that changes in fetal and placental weight with parity are strain-dependent phenomena, a suggestion supported by the data of Hetherington (1972b).

James (1967) found that placental and fetal weights in the mouse increased when the female was immunized to paternal antigens. The present findings, 
Table 1. Partial regression coefficient of the number of mouse fetuses on parity at constant age

\begin{tabular}{l|c|c}
\hline & No. of live fetuses & Total no. of fetuses \\
\cline { 2 - 3 } Natural parity & $0 \cdot 32 \pm 0 \cdot 17$ & $0.43^{* *} \pm 0 \cdot 16$ \\
Artificial parity & $0.59 * * \pm 0.24$ & $0.59 * \pm 0.25$ \\
\hline
\end{tabular}

Values \pm 1 standard error.

* Significant difference $(P<0.05)$.

** Significant difference $(P<0.01)$.

however, are in agreement with those of Clarke (1971) who reported that immunization to specific paternal antigens did not enhance placental and fetal growth.

Previous attempts to influence fetal survival by preimmunization to paternal antigens have produced conflicting results. Mitchison (1953), Woodruff (1957), Hasková (1961) and others could not demonstrate any effect on fetal survival. Breyere \& Sprenger (1969), Currie (1969) and Clarke (1971) provided evidence of an adverse effect on fetal survival. Beer \& Billingham (1973) have shown that while they could not demonstrate any effect on fetal survival, subsequent postnatal survival was severely affected by maternal preimmunization. In contrast, the results presented here demonstrate enhanced reproductive success after maternal preimmunization to paternal antigens. The different effects of preimmunization to paternal antigens found by various workers may be due to the method employed to elicit antipaternal activity. Previous attempts have been designed to maximize the response against paternally derived antigens, whereas the system used here was intended to simulate that occurring during pregnancy. The absence of any significant change in fetal death rate with immunization suggests that the increase in litter size is due to enhanced success at or before implantation. It is possible that the immunization schedule employed may have resulted in the production of enhancing-type antibodies which protect the early embryo from immunological attack before implantation, though this explanation requires that the embryo is vunerable at this stage. Beer \& Billingham (1971) have shown in the rat that sensitization to transplantation antigens occurs after intrauterine injection of homologous lymphocytes. Thus, the immune response of the mother could be initiated at fertilization and be maximal by the time of implantation. In this situation, enhancingtype antibodies might protect the preimplantation embryo.

Table 2. Partial regression coefficients of $\log _{10}$ placental and fetal weight on parity allowing for age and number of mouse fetuses

\begin{tabular}{l|c|c}
\hline & Fetal wt $\left(\times 10^{-3}\right)$ & $\begin{array}{c}\text { Placental wt } \\
\left(\times 10^{-3}\right)\end{array}$ \\
\hline Natural parity & $5 \cdot 8 * \pm 2 \cdot 6$ & $3 \cdot 4 \pm 3 \cdot 6$ \\
Artificial parity & $3 \cdot 5 \pm 4 \cdot 4$ & $6 \cdot 3 \pm 6 \cdot 2$ \\
\hline
\end{tabular}

Placental and fetal weights were measured in $\mathrm{g}$. Values \pm 1 standard error.

* Significant difference $(P<0 \cdot 05)$. 
It is claimed that antigenic differences between mother and fetus may result in enhanced fetal survival (reviewed by Beer \& Billingham, 1971). If this is correct, then immunization against such antigens should tend to increase this advantage. If embryos bearing paternally derived antigens are to be favoured, increasing immunization would be expected to result in an increase in the number of male fetuses. This, however, did not occur.

Increasing litter size with immunization might be due to increased ovulation rates. MacDowell \& Lord (1925) showed that the increase in litter size with parity in mice was probably due to increased ovulation rates. It is difficult, however, to explain how repeated immunization or non-specific factors such as trauma could increase ovulation rates or enhance fetal success before implanation, particularly as previous attempts at non-specific stimulation of the maternal immune system have either had no effect (Breyere \& Sprenger, 1969; Clarke, 1971) or an adverse effect on fetal success (Currie, 1969).

We thank Dr Anne McLaren for her helpful advice and Miss P. R. Lund and Miss J. E. Thompson for their technical assistance. This work was supported by a grant from the Medical Research Council. Dr G. Mahouy was in receipt of a grant from INSERM, France.

\section{REFERENCES}

Beer, A. E. \& Billingham, R. E. (1971) Immunobiology of mammalian reproduction. Adv. Immunol. $14,2$.

Begr, A. E. \& Billingham, R. E. (1973) Procurement of runt disease of maternal origin. Transplant. Proc. 5, 887.

BREYeRe, E. J. \& SPRENGer, W. W. (1969) Evidence of allograft rejection of the conceptus. Transplant. Proc. 1, 71.

Clarke, A. G. (1971) The effects of maternal pre-immunization on pregnancy in the mouse. F. Reprod. Fert. 24, 369.

CURRIE, G. A. (1969) The foetus as an allograft: the role of maternal unresponsiveness to paternally derived foetal antigens. In Foetal Autonomy: Ciba Foundation Symposium, p. 32. Eds. G. E. W. Wolstenholme and M. O'Connor. Churchill, London.

Goodis, R. C. \& Herzenberc, L. A. (1964) Pregnancy induced hemagglutinins to paternal H-2 antigens in multiparous mice. Transplantation, 2, 357.

Hasková, V. (1961) Relationship between tissues of mother and foetus and tissue incompatibility. Folia biol., Praha, 7, 322.

Healy, M., Mclaren, A. \& Michie, D. (1960) Foetal growth in the mouse. Proc. R. Soc. B, 153, 367.

Hetherington, C. M. (1972a) The effect of parity on decidual, placental and fetal weight in the mouse. F. Reprod. Fert. 28, 125.

Hetherington, C. M. (1972b) The effect of paternal-genotype on parity-dependent changes in the decidual cell reaction, placental weight and fetal weight in the mouse. F. Reprod. Fert. 31, 83.

JAmEs, D. A. (1967) Some effects of immunological factors on gestation in mice. F. Reprod. Fert. 14, 265.

Kaliss, N. \& DAGG, M. F. (1964) Immune response engendered in mice by multiparity. Transplantation, $2,416$.

MaCarthy, J. C. (1965) Genetic and environmental control of foetal and placental growth in the mouse. Anim. Prod. 7, 347.

MACDowelL, E. C. \& LORD, E. M. (1925) The number of corpora lutea in successive mouse pregnancies. Anat. Rec. 31, 131.

McLaren, A. \& Michie, D. (1959) Superpregnancy in the mouse. I. Implantation and foetal mortality after induced superovulation in females at various ages. 7 . exp. Biol. 36, 281.

Maroni, E. S. \& Parrotr, D. M. V. (1973) Progressive increase in cell mediated immunity against paternal transplantation antigens in parous mice after multiple pregnancies. Clin. exp. Immunol. 13, 253.

Mrtchison, N. A. (1953) The effect on the offspring of maternal immunisation in mice. F. Genet. 51, 406.

SoREN, L. (1967) Immunological reactivity of lymphocytes in multiparous females after strain specific matings. Nature, Lond. 213, 621.

Sugryama, T. (1961) Morphological studies on the placenta of mice of various ages and strains. I. Variation in foetal and placental weight at term. Acta med. Univ. Kioto, 37, 139.

Woodruff, M. F. A. (1957) Transplantation immunity and immunological problems of pregnancy. Proc. R. Soc. B, 148, 68. 